\title{
MOM is a means, not an end
}

\section{Joost Schriever}

Manager, International Marketing at temporary staffing agency Randstad, on why it's wrong to approach MOM as a way to control marketeers.

There's something about the typical marketing operations management (MOM) conversation that I find vaguely disturbing: it tends to be all about IT and how it will bring control to your marketing organisation. How product $\mathrm{X}$ will make my job a seamless, integrated state-of-the-art experience in which my branding and marketing will be fully and efficiently aligned. For me, this tendency is underlined by the fact that by inventing new names for what are basically the same solutions - when I started with MOM, three years ago, the term didn't exist; it was called MRM or branding identity management — we risk focusing on the system and forgetting that really it's just a tool to get things done.

Don't get me wrong, I love what IT provides - the ease with which I can find, create, store and retrieve information, the speed of communication, the new channels it opens up, the new opportunities - it's just that sometimes I feel that applying IT to marketing and brand management seems to have become a goal in itself. The assumption is that as long I have the 'right' software, everything else will fall magically and automatically into place.

This may be true in some companies, but not in Randstad. Randstad is a temporary staffing agency and the focus of our work is people: our clients, the people we find jobs for - and the people who work for Randstad. It's a rather tired cliché, but in our case it's true: people really are at the heart of what we do.

It was this contradiction between the way people talked about IT in branding that bothered me when, three years ago, we were looking for a software solution to support the implementation of our, then, new branding and marketing strategy. The plan was to introduce a single brand communication concept, a single motto - 'Good to know you' and a single house style across all our markets, replacing the previous ad hoc approach.

In one sense then, we wanted to run things from the centre in the usual MOM way. However, we also knew that with the temporary employment market being in various stages of development (from widely accepted in the USA, the UK and the Netherlands, to emerging in Italy and Hungary), we needed room for local adaptation and interpretation as well. But, most importantly, we knew that in Randstad's consensus-based culture, if we didn't win the support of our marketeers from the outset, it just wouldn't happen.

In my talks with suppliers, however, IT was put forward as a means to exercise control. If it wasn't being sold as a way for me to take charge of my marketers' daily work, it was being put forward as a way for the centre to wrest control of local marketing budgets (read: cut); an argument I find rather lacking in 
foresight - after all, you can also aim to get more value for your spend rather than simply trying to cut. Either way, it was always about the software. The software was a sort of magic bullet that would drive and control change. I didn't believe it.

Now, having implemented MOM in Randstad, I still don't, so I was surprised, during the Henry Stewart DAM/MOM Symposium, to discover that the IT/finance, control-based approach is still very much in the ascendant. It made me think of Douglas McGregor's Theory X and Theory Y (1960), which looked at the behaviour of individuals at work. Theory $\mathrm{X}$ was that employees are unwilling, incapable and have to be controlled, while Theory Y viewed staff as willing, capable and with a need to be inspired. It seems to me that most MOM solutions are based on a Theory $\mathrm{X}$ view of the way companies work yet many companies, Randstad included, are Theory Y-type organisations.

The point I want to make is not that I think $\mathrm{X}$ or $\mathrm{Y}$ is better - it's a choice — but that trying to impose an $\mathrm{X}$-based solution on a Y-driven culture is doomed to failure. This is why I say that it's not the software that matters, but the organisation and culture within which it is going to be applied. In a Y-behaviour company, it has to be the organisation and culture that drives the development, implementation and use of MOM software, not the other way around.

In Randstad's case, I am certain that we would never have got as far, and certainly not as fast, if we had taken a top-down, command and control approach. Randstad is a service organisation, which means that by definition we need staff that feel - and are - empowered to think on their feet and take decisions. And even though they aren't on the frontline of customer service, the same is just as true of our marketeers. They are strong individuals who are used to making choices and decisions. They know what they need and they know what's best in their market. The only way we would reap the benefits of centralisation would be to approach MOM in a way that our marketeers would see it, understand it and feel it as something to support them, not as something to control them. The brand strategy may have been based on centralisation, but the tactics for implementing it rested on supporting and facilitating our marketeers in their work.

In our case, we were lucky that, in NykampNyboer, we found a partner that shared a similar point of view. The MOM solution we went for - ID, which was developed by NykampNyboer and IT specialist Capital ID - takes the idea of providing support as its intellectual starting point.

ID is a tool to enable you to do your job more quickly and more easily. The fact that to do so you have to use certain central assets - such as the image library, house style elements and communication concept - is secondary. The way it is positioned within the organisation, the way it was introduced, the way we talk about it, the taxonomy of the tool itself and the language it uses, place the primary emphasis on sharing information. We talk about guidelines that will help you apply the brand, rather than rules that must be followed. Yes the wizards, templates and online store draw on a centralised communication concept, but they also put you in control, letting you choose how a brochure, poster, vacancy ad or other marketing tool will look within the framework of the overall concept.

The upshot is that what central control there is comes in the form of support and through being able to see how your colleagues in other country 
organisations are applying the brand, tailoring the implementation to their conditions yet doing so in a way that stays true to the principles of our communication concept. Walk into the brand room in our headquarters in Amsterdam and you will see examples of how 'Good to know you' is being applied in the UK, Germany, France, Hungary, Poland, the USA and 11 other countries in Europe, North America and Asia. You will notice differences - the USA tends to use colours more strongly than Belgium, say - but you will also see a living, breathing brand that is vividly and recognizably the same while also being in tune with local conditions and traditions.

We would never have achieved this if we had sought to use MOM as a big stick with which to control our marketeers. In fact, it is exactly the opposite - it is only by approaching MOM as a means that we have been able to achieve our ends. 